

\section{DISCLAIMER}

This report was prepared as an account of work sponsored by an agency of the United States Government. Neither the United States Government nor any agency Thereof, nor any of their employees, makes any warranty, express or implied, or assumes any legal liability or responsibility for the accuracy, completeness, or usefulness of any information, apparatus, product, or process disclosed, or represents that its use would not infringe privately owned rights. Reference herein to any specific commercial product, process, or service by trade name, trademark, manufacturer, or otherwise does not necessarily constitute or imply its endorsement, recommendation, or favoring by the United States Government or any agency thereof. The views and opinions of authors expressed herein do not necessarily state or reflect those of the United States Government or any agency thereof. 


\section{DISCLAIMER}

Portions of this document may be illegible in electronic image products. Images are produced from the best available original document. 
Printed in the United States of America. Available from National Technical Information Service

U.S. Department of Commerce

5285 Port Royal Road, Springfield, Virginia 22161

NTIS price codes-Printed Copy: A02 Microfiche A01

\section{DISCLAIMER}

This report was prepared as an account of work sponsored by an agency of the United States Government. Neither the United States Government nor any agency thereof, nor any of their employees, makes any warranty, express or implied, or assumes any legal liability or responsibility for the accuracy, completeness, or usefulness of any information, apparatus, product, or process disclosed, or represents that its use would not infringe privately owned rights. Reference herein to any sperifir rnmmerrial product, process, or service by trado namo, trademark, manu facturer, or otherwise, does not necessarily constitute or imply its endorsement, recommendation, ôr favoring by the United Slates Buvemment or any agency thereof. The views and opinions of authors expressed herein do not necessarily state or reflect those of the United States Government or any agency thereof. 
Date of Issue: August 20, 1981

\title{
INTERPOLATION ALGORITHMS FOR MACHINE TOOLS
}

\author{
R. R. Burleson
}

Fabrication Systems Department

Y-12 Development Division

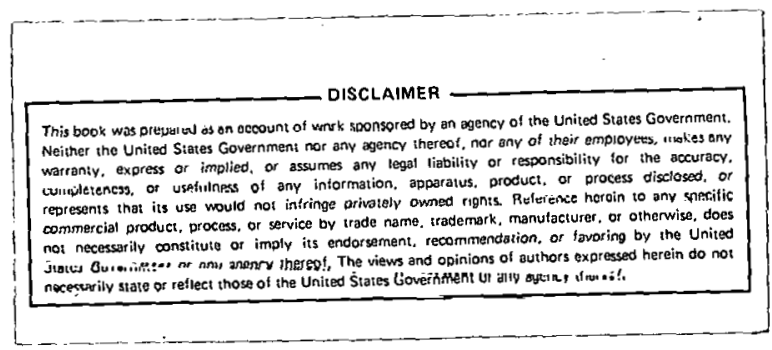

Oak Ridge Y-12 Plant

P. O. Box Y, Oak Ridge, Tennessee 37830

Prepared for the Department of Energy Under US Government Contract W-7405-eng-26 


\begin{abstract}
There are three types of interpolation algorithms presently used in most numerical control systems: digital differential analyzer, pulse-rate multiplier, and binary-rate multiplier. A method for higher order interpolation is in the experimental stages. The trends point toward the use of high-speed microprocessors to perform these interpolation algorithms.
\end{abstract}




\section{CONTENTS}

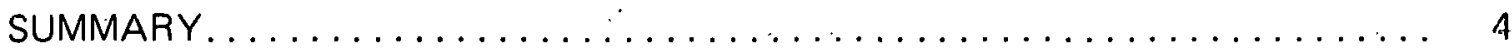

INTRODUCTION ....................................... 5

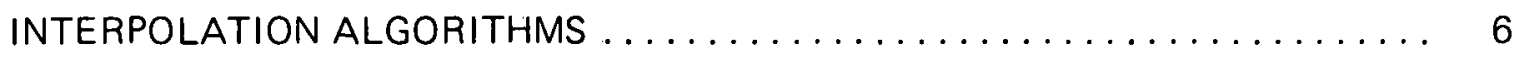

Digital Differential Analyzer.............................. 6

Pulse-Rate Multiplier................................... 9

Binary-Rate Multiplier................................. 10

Higher Order Interpolator . . . . . . . . . . . . . . . . . . . . . . . . 12

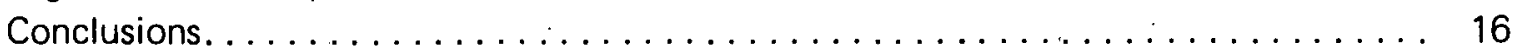

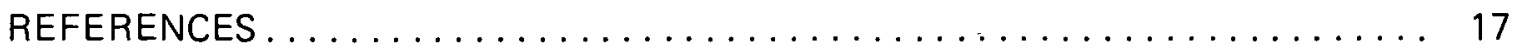

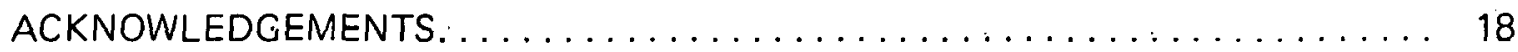




\section{SUMMARY}

Numerical control $(\mathrm{NC})$ is a method for automatically controlling machines or processes. Position and velocity commands are read from the punched tape and placed in appropriate registers of the interpolators in the machine control units (MCU). These position- and velocity-input commands are designated as departure and feed-rate words, respectively. The words are grouped into blocks of data and enter the interpolators one block at a time. The interpolators are designed to produce synchronized pulse trains from the departure words. The pulses are command signals to the closed-loop servo systems on the machine slides. The interpolators must issue these pulse trains to the axes of the machine in a sufficient amount and at a sufficient rate to accurately direct the $\mathrm{NC}$ machine along a specific line or curve. The generation of these pulse trains from input data is commonly called interpolation.

There are three types of interpolation algorithms presently used in most NC contouring control systems: digital differential analyzer (DDA), pulse-rate multiplier, and hinary-rate multiplier. A method for higher order interpolations is in the experimental stages.

The trends appear to point toward the use of high-speed microprocessors to perform the interpolation algorithms. These systems will be capable of acting as software DDAs or higher order interpolators. The advantage in using a microprocessor is the flexibility of the system and the ability to add adaptive control software to the system; i.e., soft-wired servo or acceleration-deceleration ramps. 


\section{INTRODUCTION}

Position and velocity commands of numerically controlled machines are read from the punched tape and placed in appropriate registers of the interpolators in the MCU. These position- and velocity-input commands are designated as departure and feed-rate words, respectively. The words are grouped into blocks of data and enter the interpolators one block at a time. The interpolators are designed to produce synchronized pulse trains from the departure words. The pulses are command signals to the closed-loop servo systems on the machine slides. The actual command to the slides is attained by phase comparison between feedback and command pulses and conversion of the difference to an analog signal which activates the prime mover. This prime mover can be a hydraulic motor or an electric motor. The number of pulses is equal to the commanded distance divided by the value of a single pulse. If, for example, each pulse has a value of 0.0001 in., then 10,000 pulses must be generated by the interpolator to cause a slide movement of 1 in. The frequency of the pulse train (pulses per unit time) is determined by the feed-rate word. Interpolators can produce pulses at a maximum rate which is determined by the design of the system. The feed-rate word reduces the pulse rate to some fraction of the maximum. The interpolators must issue these pulse trains to the axes of the machine in such numbers and at such a rate so as to accurately direct the NC machine along a specific line or curve. The generation of these pulse trains from input data is commonly called interpolation.

In the Oak Ridge $\mathrm{Y}-12$ Plant, (a) there are three types of interpolation algorithms used presently in most NC contouring control systems: DDA, pulse-rate multiplier, and binaryrate multiplier. An explanation of these various types of interpolation algorithms will be described. A method for higher order interpolations will also be described.

(a) Operated by the Union Carbide Corporation, Nuclear Division, for the Department of Energy. 


\section{INTERPOLATION ALGORITHMS}

\section{DIGITAL DIFFERENTIAL ANALYZER}

To automatically control machines and processes, numerically controlled, continuous-path machines, as shown in Figure 1, are used. 1 The DDA is a very popular interpolator for NC systems. The DDA is basically a digital integrator. The three main components of a DDA which are shown in Figure 2 are: (1) an integrand register, (2) an adder, and (3) a remainder register.

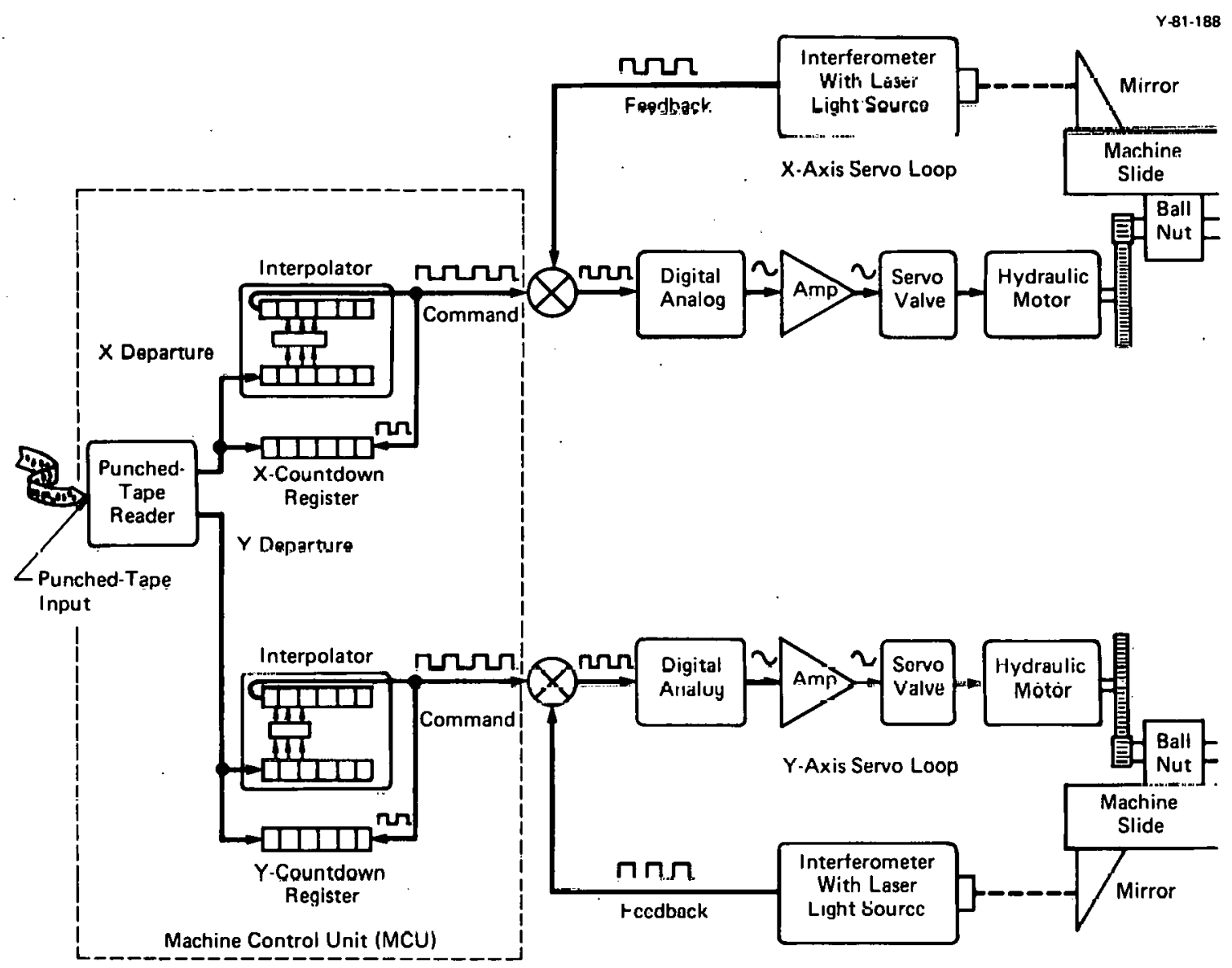

Figure 1. COMPONENTS OF A NUMERICALLY CONTROLLED MACHINE SYSTEM.

One pulse increments the integrand register contents representing one $y$ increment unit $(\Delta y)$. One command pulse to the adder represents one $x$ increment $(\Delta x)$ and causes the addition of the current integrand, $y$, to the remainder. Continual addition to the remainder causes it to overflow its register, periodically, at a rate determined by the rate of $\Delta x$ inputs and by the magnitude of the integrand $y$. Over a specific time period, the sum of the overflows approaches the rectangular approximation, Simpson's rule, of the integrals of $y$ and $x$ with respect to time. 
Let the distance from Point $A$ to Point $B$ be $150 \mu \mathrm{in}$. Movement from $A$ to $B$ with a $25-\mu \mathrm{in}$. resolution would require six pulses to the motor. The six. pulses are generated by loading the integrand register with the binary number (110). A marker bit is added to the right of the binary number to indicate when the six pulses have been generated. Thus, the actual binary number, stored in the integrand register is 1101 . The remainder register is cleared and added to the integrand, and the result is stored in the remainder register. Successive additions are made until the marker bit appears in the "leftmost" bit position and zeroes appear in the remaining bits. An example of this technique is shown in Figure 3. Movement pulses are generated by detecting a carry from the addition. When the sixth pulse is generated, the 150 $\mu$ in. movement from Point $A$ to Point $B$ would be completed.

A two-axıs ( $x$ - and $y-)$ continuuus-jalli machinc with linear interpolation would require two DDAs. As shown in Figure 4, the incremental distance $\Delta x$ is put into the integrand register of one DDA, and the distance $\Delta y$ is put into the integrand register of the other DDA. The values $\Delta x$ and $\Delta y$ are added to the respective remainder registers every $\Delta t$ period of time. The resultant movement caused by the overflows from the $x$ and $y$ remainder registers will be along a vector of slope $\Delta y / \Delta x$ at a rate dependent upon the frequency of the $\Delta t$ addition commands.

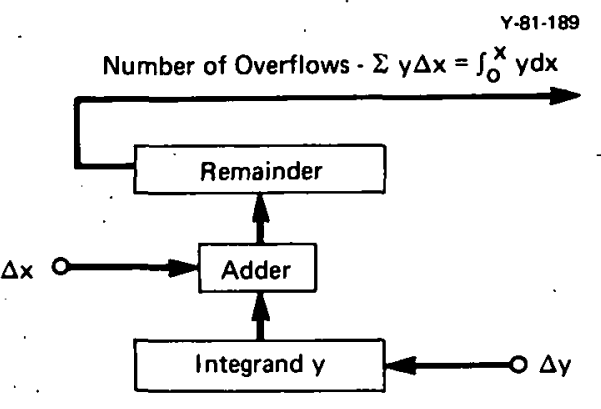

Figure 2. A DIGITAL INTEGRATOR.

\begin{tabular}{lrr}
$\begin{array}{lrl}\text { Remainder Register } \\
\text { Integrand Register }\end{array}$ & $\begin{array}{c}0000 \\
+\frac{1101}{1101}\end{array}$ & Addition 1 \\
Pulse 1 & (1) $\frac{1101}{1010}$ & Addition 2 \\
Pulse 2 & (1) $\frac{1101}{0111}$ & Adrdition 3 \\
Pulse 3 & (1) $\frac{1101}{0100}$ & Addition 4 \\
Pulse 4 & (1) $\frac{1101}{0001}$ & Addition 5 \\
Pulse 5 & $\frac{1101}{1110}$ & Addition 6 \\
Pulse 6 & (1) $\frac{1101}{1011}$ & Addition 7 \\
\hline
\end{tabular}

Figure 3. DIGITAL-INTEGRATOR ARITH METIC. The frequency of the $\Delta t$ addition commands is determiried by the feed-ratc number in the block. of data.

An extension of linear interpolation allows achievement of synchronous movement along the arc of a circle. Figure 5 portrays the connection of two DDAs to generate the coordinates of an arc; i.e., circular interpolation. The overflow pulses from each integrator are gated to the integrand register of the other, while the output pulses are fed to the appropriate machine slides.

In Figure 5 , if the product of $R$ and $\sin \theta$ is put into Integrator 1 and the product of $R$ and $\cos \theta$ is put into Integrator 2 (where $R$ is the radius of the desired arc and $\theta$ is the angle between the $x$-axis and the radius vector), then any point on the arc is defined by the values $x=R \sin \theta$ and $y=R \cos \theta$; i.e.,

$$
x=R \cdot \int \cos \theta d \theta=R \sin \theta \text {, and }
$$




$$
y=R \int \sin \theta d \theta=-R \cos \theta .
$$

Thus, if the two integrators integrate the quantities $\mathrm{R} \sin \theta$ and $\mathrm{R} \cos \theta$ continuously, the coordinates ( $x$ - and $y$-) will define an arc if the overflows of each integrator are fed to the other. One prime advantage of circular interpolation is the reduction of data requirements to direct a machine along a circular path. Only one block of data is necessary to command a machine to traverse a $90^{\circ}$ arc in a quadrant. A further extension of linear interpolation allows us to achieve synchronous movement along the arc of a parabola. ${ }^{2}$

Figure 6 gives the flow pattern of a simplified DDA circuit for parabolic interpolation. Essentially, a constant $x$ acceleration is being integrated twice to get $x$ as a function of time in the form:

$$
x=\frac{a t^{2}}{2}+v_{0} t+x_{0}
$$

The equation represents a parabolic motion in time. If such a motion is applied to two orthogonal axes of a machine tool, a parabolic motion in space will result. The desired motion is obtained through proper selection of the constants: $a, v_{0}$, and $x_{0}$.

The integrators operate in a fixed cycle. One cycle of operation is called an iteration. An iteration consists of the following items (for each axis, separately but simultaneously):

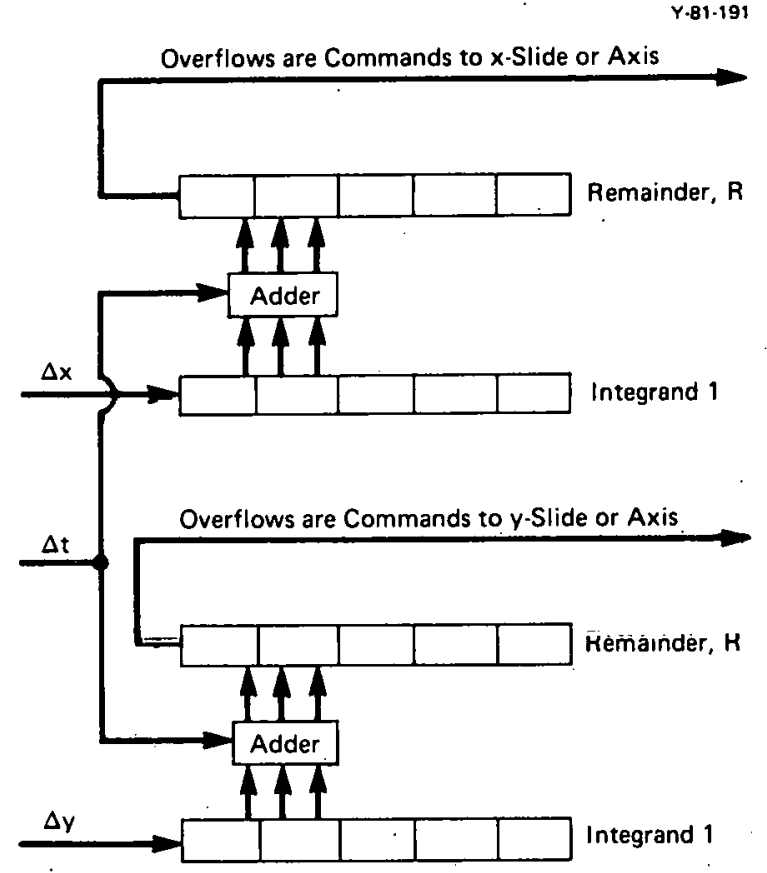

Figure 4. TWO DIGITAL DIFFERENTIAL ANALYZERS USED FOR LINEAR INTERPOLATION.

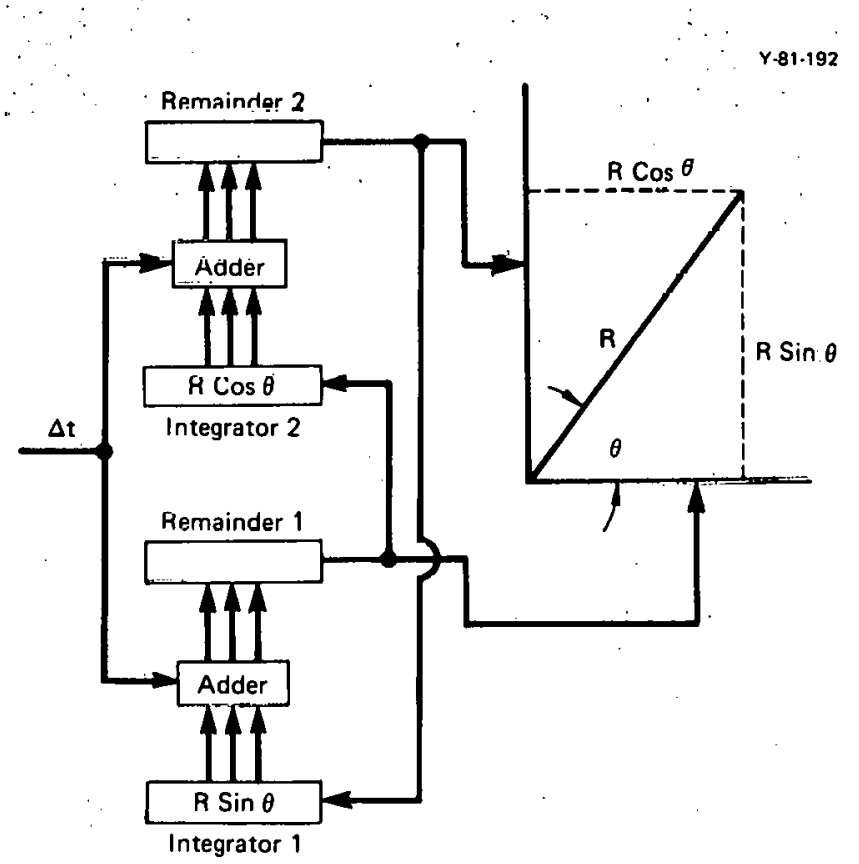

Figure 5. CIRCULAR INTERPOLATION WITH TWO DIGITAL DIFFERENTIAL ANALYZERS.

1. Overflow of the acceleration remainder from the previous iteration, if any, is added to the velocity integrand. 
2. The clock, which is running at a specified and constant rate, sends a command pulse to both adders simultaneously. Both integrands are added to their respective remainders.

3. Overflow from the velocity remainder, if any, is sent to the $x$-slide motor as a command pulse.

The parabolic interpolator has the advantage of directing the NC machine along a long span with just two blocks of data. The disadvantage of parabolic interpolation is the necessity of determining the end points and the midpoint prior to input into the interpolator.

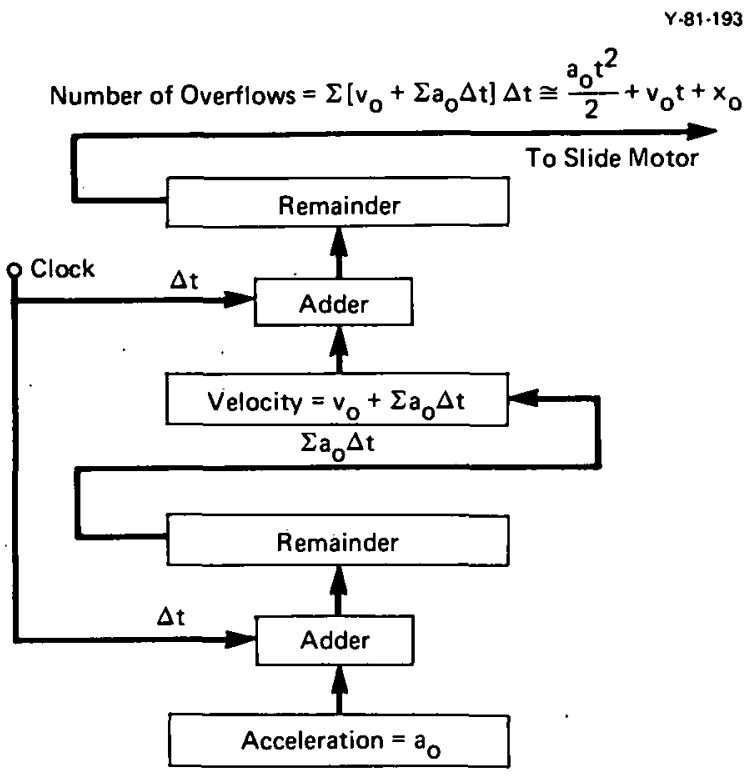

Figure 6. A SIMPLIFIED, DIGITAL-DIFFERENTIALANALYZER, PARABOLIC INTERPOLATOR.

A major advantage in using the DDA as an interpolator is its versatility. Several DDAs can be interconnected to perform either linear, circular, or parabolic interpolation. These DDAs could consist of either hardware registers and adders or software programs in a highspeed microprocessor. Using software, DDAs allow the MCU to change from one type of interpolation to another type; i.e., linear to circular by simply executing a different stored program. With the advent of inexpensive high-speed microprocessors, this appears to be the trend of the future.

\section{PULSE-RATE MULTIPLIER}

Ariother commonly used interpolator is the pulse-rate multiplier (PRM). Figure 7 depicts the basic elements of a three-decade PRM. The PRM is triggered by $\triangle \mathrm{t}$ pulses and the output is a series of pulses issued on a summation line. The rate of $\Delta t$ pulses is, as was the case for the DDA, determined by the feed-rate number in the block of data. The counters are designed such that the counter to the right is triggered to count once every time the counter to its left counts 10 times. Therefore, if in Figure 7, the counter to the far left is triggered 1000 times, the middle counter will be triggered 100 times, and the counter to the far right will be triggered 10 times. The gating of the PRM is designed such that a number of pulses equal to the value in the command block will be issued along the summation line every time its associated counter cycles from $U$ through 9 ( 10 pulses).

Hence, if the number 724 was put into the command blocks in Figure 7, 700 pulses would result from the first counter-gate-command group on the summation. line, 20 from the second group, and 4 from the third group. 


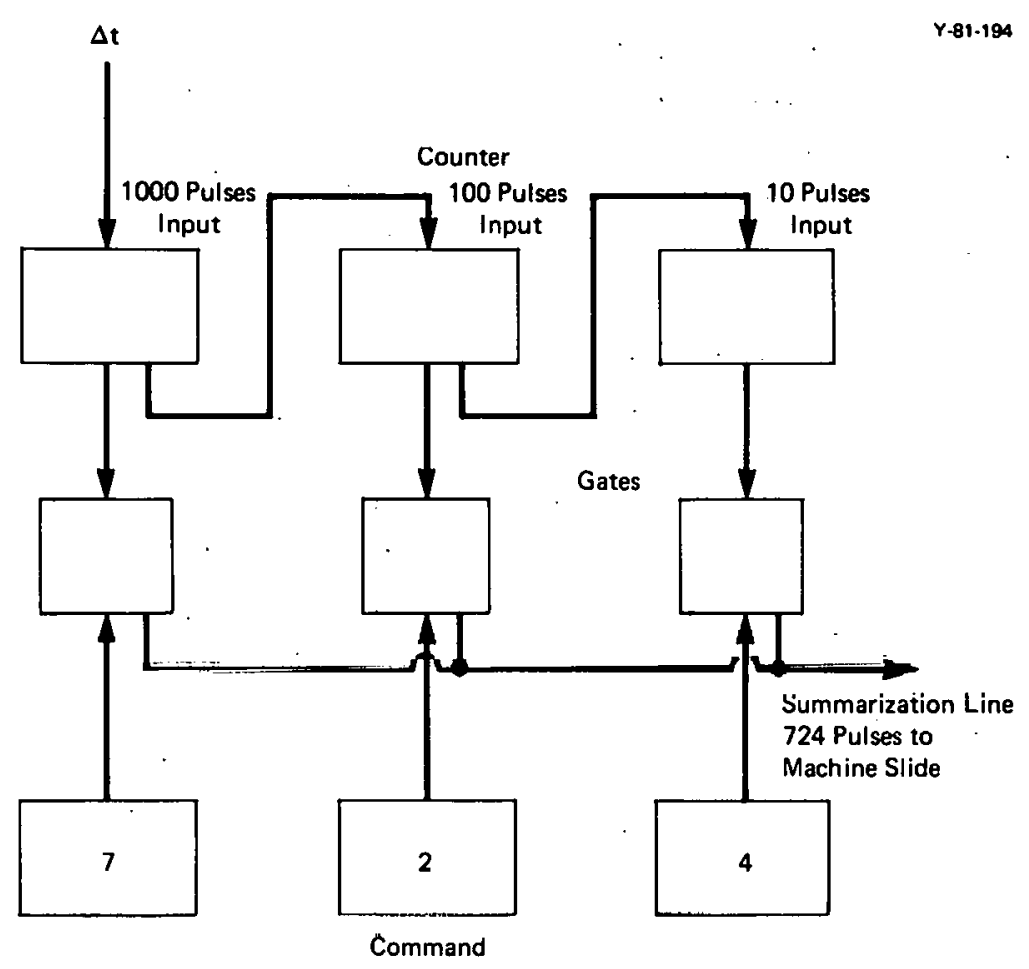

Figure 7. PULSE-RATE MULTIPLIER.

\section{BINARY-RATE MULTIPLIER}

A third type of interpolation device is the binary-rate multiplier (BRM) or binary-operational multiplier (BOM). A BOM is depicted in Figure 8. The BOM is designed to accept a pulse train at one input and a numeric code at the other to yield a new pulse train containing a number of pulses equal to llie pruduct of the number of input pulses (multiplicand) and the numeric code (multiplier). If a pulse train, $\Delta t$, is applied to the first binary flip-flop so that in a given interval of time $x$ pulses occur, the scalar outputs of each binary flip flop during the interval in which $x$ input pulses arrive are $x / 2, x / 4, x / 8, \ldots$. $x / 2^{n}$ pulses. The sum of these output pulses is:

$$
\sum_{i=1}^{n} \frac{1}{2^{i}}=1-\frac{1}{2^{n}} .
$$

Therefore:

$$
\sum_{i=1}^{n} \frac{1}{2^{i}}=1 \text {, as } n \rightarrow \infty \text {. }
$$

These scalar outputs are applied to gates which are opened or closed according to the multiplier, y, where: 


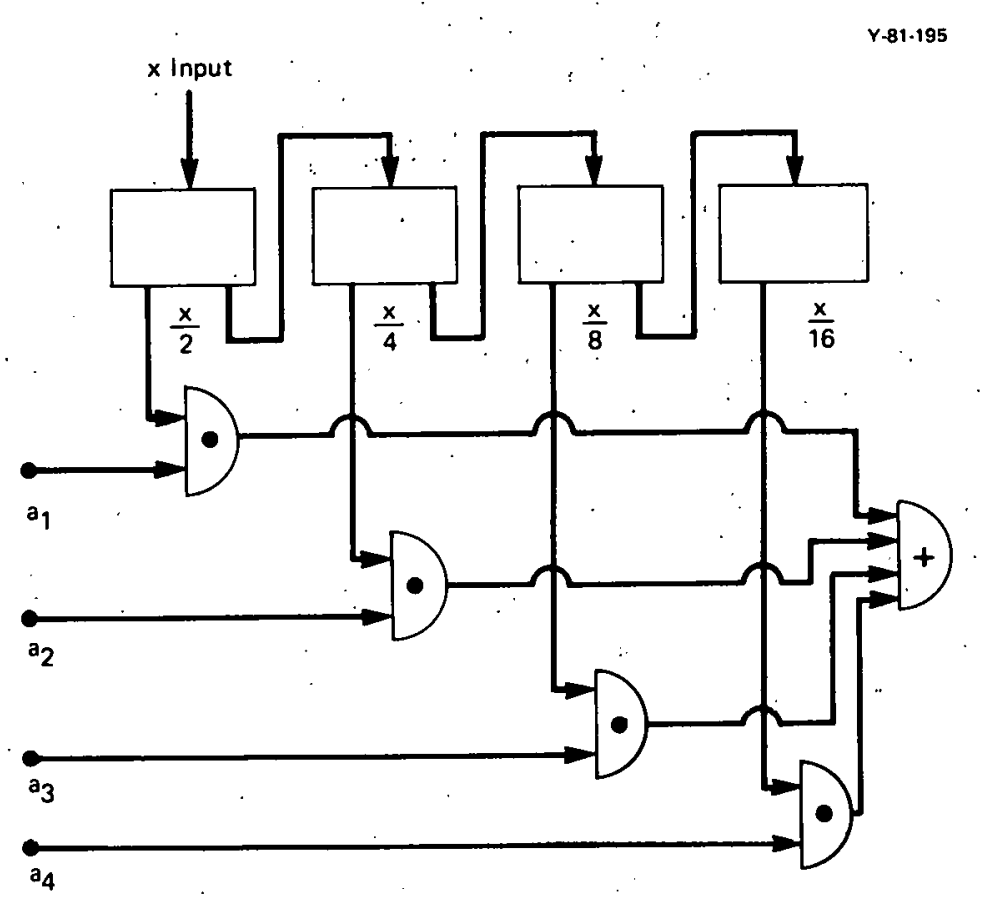

Figure 8. BINARY-OPERATIONAL MULTIPLIER.

$$
Y=\sum_{i=1}^{n} \frac{a_{i}}{2^{i}}
$$

The output of the gates are combined to yield a sum of pulses equal to:

$$
a_{1} \frac{x}{2}+a_{2} \frac{x}{4}+a_{3} \frac{x}{8} \cdots+a_{n} \frac{x}{2^{n}}
$$

which is actually the product of $x$ and $y$, as may be shown by the relation:

$$
x y=\sum_{i=1}^{n} \frac{x}{2^{i}}=x \sum_{i=1}^{n} \frac{a_{i}}{2^{i}} .
$$

It should be recognized that $y$ is always less than unity. If $y=0$, its binary code is $0.000 \ldots 0$. All gates are, therefore, closed; and no pulses will appear at the output of the multiplier. If $y=1$, its binary approximation is $0.111 \ldots 1$. In this case, all gates are open; and all of the scalar output pulses will appear at the product output. If $y=0.6250$, its binary code is 0.101 (i.e., $1 / 2+1 / 8$ ) so that $1 / 2$ of the input pulses plus $1 / 8$ of the input pulses will be gated to the output. For $x=1000,625$ pulses will be produced. 


\section{HIGHER ORDER INTERPOLATOR}

Mathematical analyses, described next, demonstrate the need for a truly hyperbolic interpolation scheme. Traditional interpolators are not able to perform this function since it is not possible to generate a hyperbola by interconnecting digital integrators. A microprocessor-based interpolator, fortunately, is capable of performing a variety of digital functions in addition to simple integration. The following discussion concerns work being done at the $\mathrm{Y}-12$ Plant in support of the laser fusion program.

This facility will feature on-the-floor part programming for finish-cutting parabolic, hyperbolic, elliptic, and spherical shapes to optical tolerances. The input to the system will be "equaliur defined" in that only the coetticients of the defining equation will be needed. This section will discuss the mathematical analysis in going from the defining equation to the final marhining data. 2

A standard notation and part orientation will be used in the subsequent work. The pertinent facts are summarized in Figures 9-12. The symbol $p(x)$ will denote the radius of curvature at Position $x$, the symbol $\epsilon$ will denote the eccentricity parameter, and $p$ will denote the focal length.

This system will have the capability to produce a parabolic or hyperbolic motion of the cutting tool from one block of machining data. This feature is called parabolic or hyperbolic interpolation (or simply higher order interpolation) in contrast with the traditional technique which produces only linear motion. The impact for the discussion

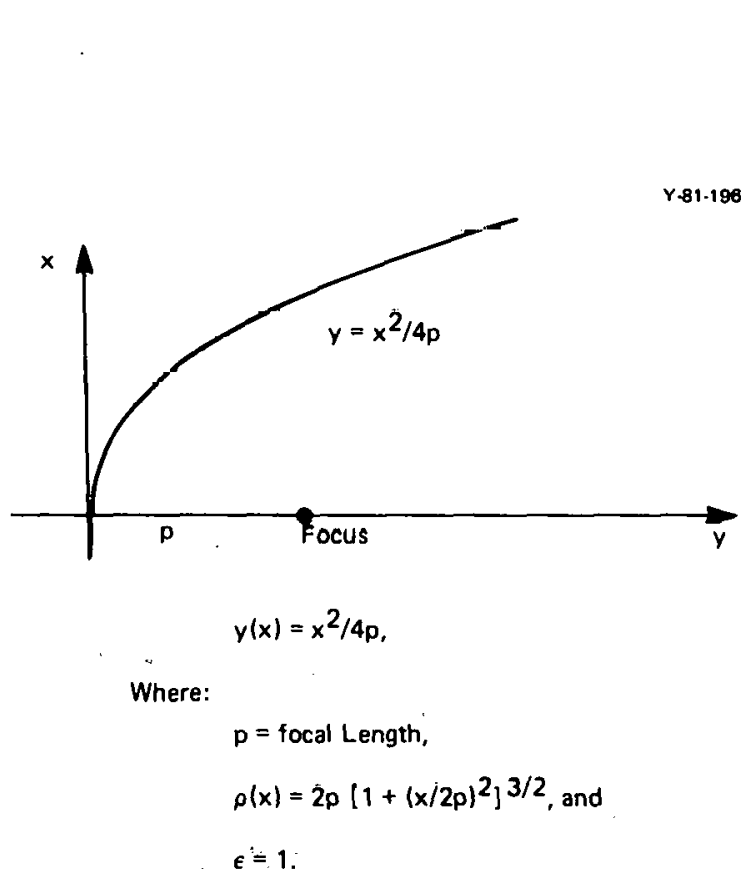

Figure 9. STANDARD PARABOLA.

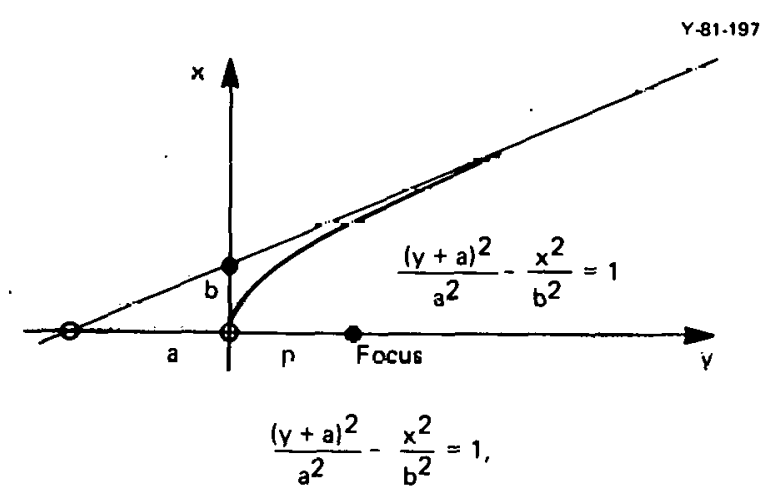

Or:

$$
\begin{aligned}
& y(x) \equiv a\left\{\left[1 \neq(x / b)^{2}\right] 1 / 2 \cdot 1\right\} . \\
& \rho(x)=\left(b^{2} / a\right)\left\{1+\left[1+(a / b)^{2}\right](x / b)^{2}\right\}^{3 / 2}, \\
& p=\left(a^{2}+b^{2}\right)^{1 / 2}-a, \text { and } \\
& c=\frac{\left(a^{2}+b^{2}\right)^{1 / 2}}{a}>1 .
\end{aligned}
$$

Figure 10. STANDARD HYPERBOLA. (Figure illustrates branch of the hyperbola which will be used.) 

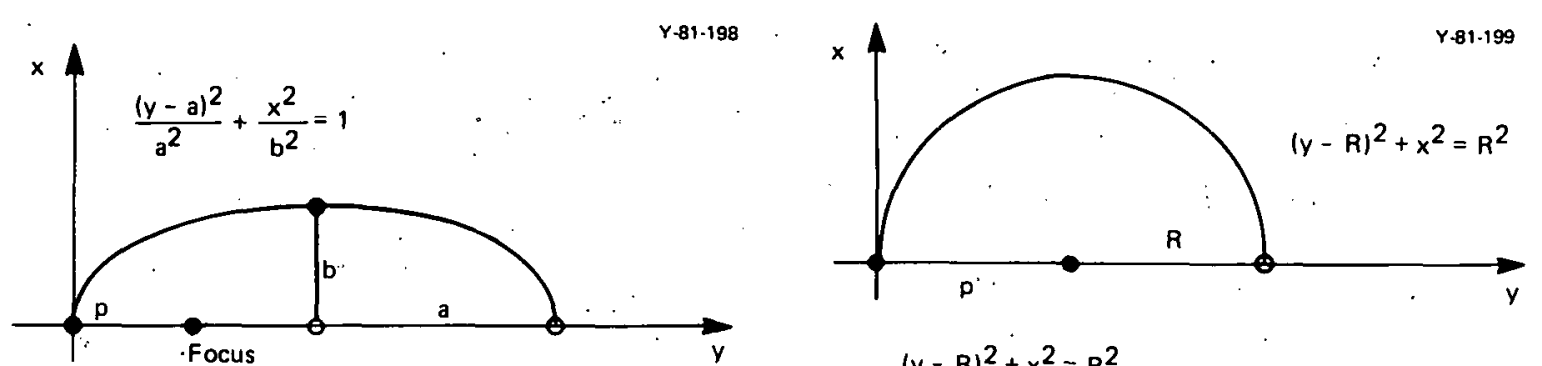

$$
\frac{(y-a)^{2}}{a^{2}}+\frac{x^{2}}{b^{2}}=1
$$

$$
(y-R)^{2}+x^{2}=R^{2}
$$

Or:

Or:

$$
\begin{aligned}
& y(x)=a\left\{1-\left[1-(x / b)^{2}\right]^{1 / 2}\right\},-b \leqslant x \leqslant b . \\
& \rho(x, y)=\left(b^{2} / a\right)\left\{(1-y / a)^{2}+\left(a / b^{2}\right)^{2} x^{2}\right\}^{3 / 2}, \\
& p=a-\left(a^{2}-b^{2}\right)^{1 / 2} \text {, and } \\
& \epsilon=\frac{\left(a^{2}-b^{2}\right)^{1 / 2}}{a}<1 .
\end{aligned}
$$

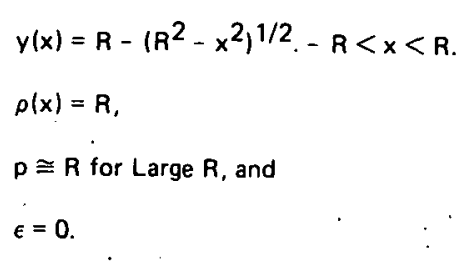

Figure 12. STANDARD CIRCLE.

Figure 11. STANDARD ELLIPSE.

here is that any part shape to be cut may now be approximated by a series of parabolic or hyperbolic arcs.

Figures 9-12 show characteristic conic-section shapes. Technically, this facility will finish cut such shapes, but the finished product will have the appearance of a flat surface. This result is because the regions of interest in Figures 9-12 are comparatively narrow areas centered on the origin wherein the shapes are nearly flat. For illustration, the depths of 0.5-m (20-in.)-diameter conic-section mirrors with 7.5-m (300-in.) focal lengths were calculated, with the following results: parabola - $2.11 \mathrm{~mm}(83.33 \mathrm{mils})$, hyperbola $2.06 \mathrm{~mm}$ ( $81.30 \mathrm{mils}$ ), ellipse $-2.23 \mathrm{~mm}$ (87.98 mils), and circle $-4.23 \mathrm{~mm}$ (166.71 mils). These depths decrease and approach a common value as the focal length is increased.

Figure 13 illustrates parabolic versus straight-line approximation of an arbitrary curve.

It is apparent from Figure 13 that a parabolic arc will satisfactorily approximate an arbitrary contour over a greater range than will any straight-line segment, with the result that much less machining data are required for a given contour. Less apparent is the fact that the parabolic approximation is continuous in both position and slope, which should result in an improved surface finish (the traditional, straight-line approximation is discontinuous in slope).

Figures 9-13 point up two important facts: (1) the parabola is a very good approximation for the other shapes, and (2) conditions can arise wherein all shapes are the same within the resolution of this machine $[6.25 \mathrm{~nm}(0.25 \mu \mathrm{in})$.$] . For an example of the latter fact,$ a calculation was made which showed that a $0.16-\mathrm{m}$ (6.4-in.)-diameter, 7.6-m (300-in.)focal-length hyperbola could be approximated by a single parabolic arc to within $6.25 \mathrm{~nm}$ 
(0.25 $\mathrm{min}$.). Another calculation showed that the 600-in.-focal-length parabola and hyperbola were within $1 \mu \mathrm{in}$. of each other, well past a $0.25-\mathrm{m}$ (10-in.) diameter. It should be clear that extremely low contour errors will have to be held in order to obtain mirrors which will focus at all-even more essential for a sharp focus.

The term, parabolic interpolation, as applied to the machine tool and its

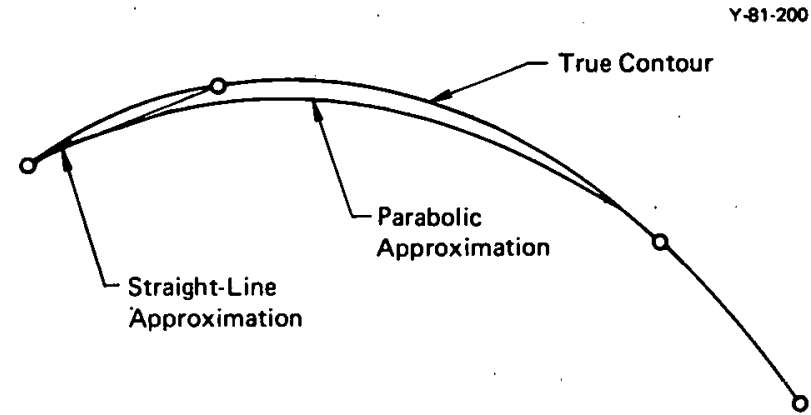

Figure 13. PARABOLIC VERSUS. STRAIGHT-LINE APPROXIMATION OF A CONTOUR. control system, means that a parabolic tool motion cạn be produced from a single block of data. This sootion will discus3 the mieroprocessor teclinique vulich produces the drlve signals for parabolic and hyperbolic motions.

Basically, the problem is as follows: The $x-y$ motions on the machine-tool fixture are controlled by pulsed drive motors which produce a small fixed increment of motion for each drive pulse. Linear motion is produced when both axes receive a series of pulses equally spaced in time. Parabolic (hyperbolic) motion is produced when the $x$-axis receives a series of pulses equally spaced in time and the $y$-axis receives a series of pulses whose time spacing increases parabolically (hyperbolically). Some means must be devised for producing the latter unequally spaced pulse trains.

An approach was chosen wherein an inexpensive fast microprocessor is dedicated to running an interpolation routine at a fixed, but controllable, rate. The routine is iterative, and outputs an $x$-drive pulse on each iteration. The $y$-drive pulses, however, are output only on parabolically (or hyperbolically) spaced iterations. Since the iteration is carried on at a fixed rate, the pulse spacing is the same in time, also. as desired.

The parabolic (or hyperbolic) interpolation algorithm is as follows, leaving out considerahle detail.

1. Rèad a block of data.

2. Set the iteration rate.

3. Initialize the $x, y$ positions.

4. Send out an $x$-drive pulse.

5. Update the true $x$ position.

6. Is the current y position less than a true curve? 
7. Send out the $y$ drive. If no, go to Step 4.

8. Update the y position.

9. Is travel done for this block? If no, go to Step 4; if yes, go to Step 10.

10. Are all blocks processed? If yes, stop; if no, go to Step 1 .

What is important to note is that this algorithm must be written without using multiply or divide instructions, which are not available in hardware on the microprocessor, and that it must be made as compact as possible in order to meet the speed requirements. For example, if it is required that a $6-\mathrm{mm} / \mathrm{min}(0.25-\mathrm{in} . / \mathrm{min})$ surface speed be generated; and if the pulse resolution is $6 \mathrm{~nm}\left(0.25 \mu \mathrm{in}\right.$.), then the $x$-axis drive must have very nearly $6 / 6 \times 10^{-6}=10^{6}$ pulses/second as input. From this development, it is apparent that the iteration rate for the interpolation algorithm must be $10^{6}$ /second. Since the algorithm requires on the order of 20 microprocessor instructions, the speed of execution must be $20 \times 10^{6}=2 \times 10^{7}$ instructions/second, or $50 \mathrm{~ns} /$ instruction. The latter is a worst-case estimate.

A computer program is being written which will converse with the operator at the machine and will generate the machining data given only the coefficients of the equation-defined curve. The main challenge in this task is that the machining-data values must have 48-bit precision and must be scaled and shifted properly within the 48-bit spaces. A second challenge is to write a fast; compact, routine-blocking algorithm which will take an equation-defined curve and approximate it by a series of parabolic or hyperbolic arcs which are continuous in position and slope.

The blocking algorithm uses the following assumptions about the problem and this facility:

1: Only shallow hemisphere-type parts will be considered.

2. No slide reversal will occur while cutting the actual contour.

3. The part orientation will always be as shown in Figures 9-12.

4. The smallest radius of curvature will occur at the pole.

5. There is no interest in calculating the absolute minimum numbers of data blocks; but, instead, interest lies in the smallest number of blocks which can be obtained economically in terms of computer time and memory space.

The blocking algorithm uses the assumptions just enumerated and performs the following steps (parabola case):

1. Calculates a maximum travel distance by iteration with the worst-case radius of curvature: assumes minimum travel, fits the parabola to the end points, and checks the 
errors with the true curve. If error does not exceed tolerance, double travel, refit parabola, and perform other. operations until the tolerance is exceeded, then use the last travel which did not cause the tolerance to be exceeded.

2. Breaks up into blocks using the maximum travel found in Step 1. Fits the parabola to each block and checks the error with the true curve. If the tolerance is exceeded, cut the travel in half and try again. The latter step should rarely be necessary.

3. Calculates the values needed by the microprocessor interpolator algorithm and converts them to a three-word integer form, properly shifted. Stores the information in a dish file for later use by the machine-control system. The block parabolic parameters will be in the form of floating-point double-precision constants.

Contour errors will be corrected by adjusting the hlock. endpointe by the arrount of the obsorvod crror and then by ievuiily Sieps 2 and 3. This approach will be possible because the computer will be interfaced to a laser-interferometric contour-measurement system which is mounted on the machine tool. The amount of calculation time should be on the order of 1 minute between machining passes.

\section{CONCLUSIONS}

In the early days of NC, interpolation was a major concern since a control unit was either linear, circular, or parabolic. With the advance in control-unit design and the advent of compuiter numerical control ( $\mathrm{CNC}$ ), a tremendous amount of flexibility has been added th control units. A user can now change the type of interpolation done by modifying the software of his CNC unit.

The trends appear to point toward the use of high-speed microprocessors to perform the interpolation algorithms. These systems will be capable of acting as software DDAs or higher order interpolators. The advantages in using a microprocessor are the flexibility of the system and the ability to add adaptive control software to the system; i.e.; soft-wired servo or acceleration-deceleration ramps. 


\section{REFERENCES}

1. R. V. Miskell, Cubic Interpolation for Numerically Controlled Machines, Union Carbide Corporation, Nuclear Division; Oak Ridge Y-12 Plant, Oak Ridge, Tenn., Y-1782 (1971).

2. C. M. Davenport, UltraPrecision Parabolic Interpolator for Numerically Controlled Machine Tools, Union Carbide Corporation, Nuclear Division, Oak Ridge Y-12 Plant, Oak Ridge, Tenn., Y-2066 (1977). 


\section{ACKNOWLEDGEMENTS}

The author wishes to thank C. M. Davenport of the Instrumentation and Characterization Department, Y-12. Development Division, Oak Ridge Y-12 Plant, for his mathematical analysis of the higher order interpolation algorithm. 


\section{Distribution.}

Department of Energy - Oak Ridge:

Hickman, H. D.

Poteat, R. M.

Lawrence Livermore National Laboratory

Arnold, W: F.

Bender, C. F. Ernst K.

Clough, R. E./Galles, H. L.

Corallo, R. A./Grissom, M. L.

Ludwig, E. R.

Mara, G. L.

Robbins, J. L.

Root, G. S./Sanford, C. B.

Shuler, W. B./Wraith, C. L.

Simecka, W. B./Carr, R. B.

Technical Information Division

Werne, R. W.

Woodruff, R. D./Scanlin, W. F.

Los Alamos National Laboratory

Hovt. H. C.

Oak Ridge Gaseous Diffusion Plant

Armstrong, R. C.

Stief, S. S.

Wilcox, W. J., Jr.

Oak Ridge National Laboratory

Hopkins, C. C.

Oak Ridge Y-12 Plant

Barkman, W. E.

Burditt, R. B.

Davenport, C. M.

Dickert, R. P.

Dixon, J. H.

Dodson, W. H./Googin, J. M.

Foulk, D. L.

Jones, F.W.

Keith, A.

Kite, H. T.

Mills, J. M., Jr.
Neal, R. E.

Robinette, B. K.

- Steger, P. J!

Stephens, A. E:

Thompson, C. H.

Williams, T. L.

Wright, C. C:

$Y=1,2$ Central Files, (master copy)

$Y-1,2$ Central; Files (route copy)

$Y=12$ Central Files $(Y=12 R C)$

$Y-12$ Central; Files (5)

Paducah Gaseous Diffusion Plant

Walter, C. W:

Sandia National Laboratories = Albuquerque

Spenceri: W: J.

Union Carbide Corporation = New York:

Tinsley, S. W.

In addition, this report is distributed in accordance with the Category UC. 38 , Engineering and Equipment, as given in the Standard Distribution for Unclassified Scientific and Technical Reports, DOE/TIC -4500 . 